\title{
Comparison of Shaft Fire Experiment and CFD Modelling
}

\author{
MAREK POKORNY ${ }^{1}$, BJARNE PAULSEN HUSTED ${ }^{2}$, and ARJEN KRAAIJEVELD ${ }^{2}$ \\ ${ }^{1}$ Department of Building Structures \\ Czech Technical University in Prague - Faculty of Civil Engineering \\ Prague 6 - Dejvice, 7/2077 Thakurova, Czech Republic \\ ${ }^{2}$ Department of Engineering \\ Stord / Haugesund University College (HSH) \\ Haugesund, 45 Bjørnsonsgate, Norway
}

\begin{abstract}
The paper deals with the comparison of the first series of data, measured in a laboratory shaft model, with the results gained by mathematical modelling. From its cross-sectional dimensions, the half-scale shaft model corresponds to an apartment plumbing shaft in residential buildings and its height corresponds to approximately one and a half storeys. This situation is modelled by the Fire Dynamics Simulator (FDS) software using the principles of computational fluid dynamics (CFD). The measured and simulated results of temperature, total heat flux and flow velocity distributions for the tall narrow shaft space are presented. A mutual comparison between the laboratory measurements and the simulation is provided and discussed. The paper also presents a basic structural solution for plumbing shafts partially related to the experiment and problematic combustible utility cores, including plumbing shaft spaces in older prefabricated blocks of apartments in the Czech Republic.
\end{abstract}

KEYWORDS: shaft, utility core, heat transfer, flow velocity, modelling, CFD, flame spread, FDS.

\section{INTRODUCTION}

Large-scale construction of prefabricated blocks of apartments in many variants was implemented in the Czech Republic in the second half of the $20^{\text {th }}$ century during the communist era. Up to the present time, many serious events have been observed, where fire spreads between apartments and storeys via vertical plumbing shafts [1]. Nowadays, no statistical data for this type of buildings is provided but fires in residential buildings reported only for the year 2009 represented about $17 \%$ of all fires -2471 fire events, 262 people were killed, 442 people were injured and material damage amounted to about EUR 14.4 million [2].

In the abovementioned buildings, different types of prefabricated laminate-systems (Fig. 1) are used for partitions of utility cores (WC, bath) including partitions around plumbing shafts. These systems are highly combustible. The inner shaft spaces were constructed with concrete barriers at floor level. The original incombustible plumbing is being replaced by new combustible plumbing and the concrete barriers are frequently damaged or even removed. Generally speaking, these barriers cannot replace fire sealing systems and they can only restrict the spread of a fire, however they cannot completely prevent the spread of a fire by the chimney effect. Nowadays, the original utility cores remain a significant problem.

A better understanding of the fire spread mechanism through a shaft space provides a good reason for the chosen type of experiment. Zone modelling is a very frequent and useful method in fire engineering practice. It is more user friendly in comparison with CFD modelling but it has its limitations too. Generally, zone models are not appropriate for fire simulations of spaces with one dominant dimension (e.g. shafts or tunnels). The reason for this is a different behaviour of the 'fire plume' (the vertically rising plume of smoke and hot gases from a fire) in comparison with a space where no dimension dominates (e.g. a room or atrium). In the case of a shaft, the air entering a fire plume and its general behaviour are markedly affected by adjacent shaft walls. 


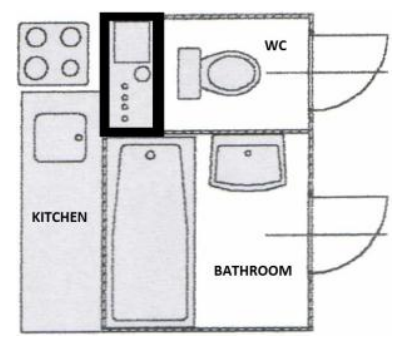

(a)

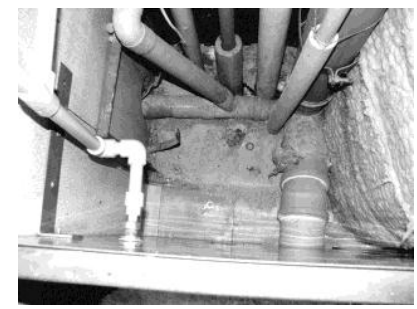

(b)

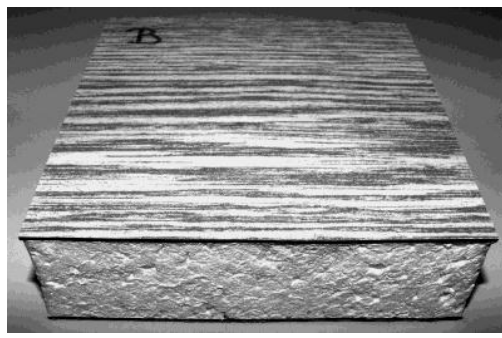

(c)

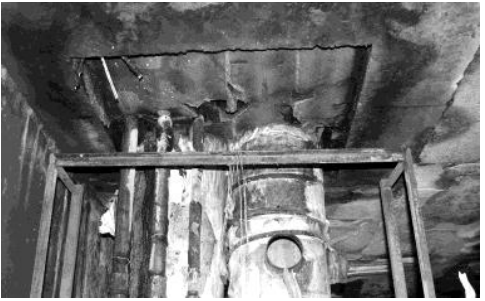

(d)

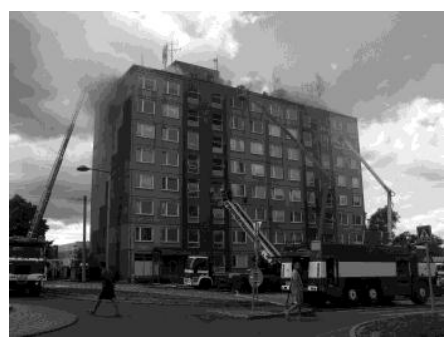

(e)

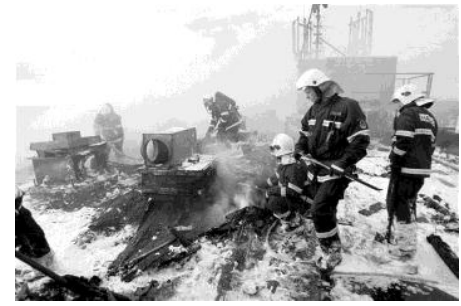

(f)

Fig. 1. Current problematic utility cores and plumbing shafts in a prefabricated block of apartments in the Czech Republic: (a) plan of a utility core (the black rectangle marks a plumbing shaft); (b) plumbing shaft space as seen through an inspection door; (c) sample $(100 \times 100 \mathrm{~mm})$ of a combustible wall system removed during apartment reconstruction (polystyrene core and surface multilayer composite material of rough cellulose papers layers and coloured melamine or formaldehyde resin); (d) burnt shaft covering and ceiling concrete barrier after a fire; (e) and (f) fire spread through a plumbing shaft on a timber roof structure.

\section{STRUCTURAL SOLUTION OF SHAFTS IN TERMS OF FIRE SAFETY}

Generally, plumbing shafts are chimney-like spaces and they are used for vertical building services (sanitary plumbing, wiring, ventilation, etc.). The shafts interconnect various spaces (fire compartments) over the height of a building and create significant risk of vertical fire spread, especially in residential or civic buildings due to the chimney effect. Incombustible materials were used for plumbing in former times, for example steel ducts for cold and hot water, cast-iron ducts for sanitary plumbing or sheetmetal ducts for ventilation. Nowadays, plastic materials are mostly used (polypropylene, polyethylene, soft and normal polyvinyl-chloride, foam plastics for thermal insulation of plumbing, etc.). There is a large variety of combustible materials in a small cross-section shaft area and these materials are characterized by considerable development of smoke and toxic products during a fire. Plastic materials can drip away and fall off thus contributing to a subsequent spread of a fire.

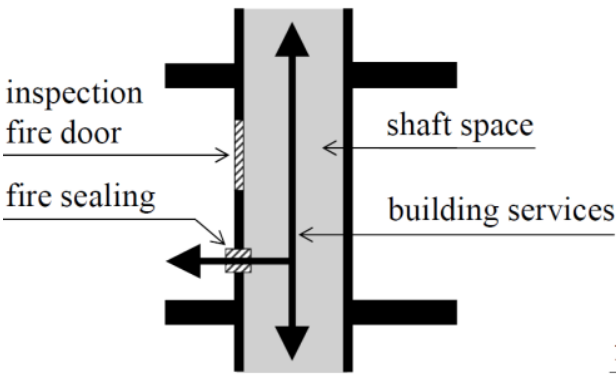

(a)

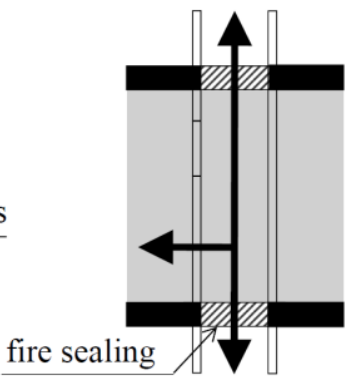

(b)

Fig. 2. Basic structural solution of plumbing shafts: (a) continuous shaft; (b) separated shaft.

In reality, plumbing shafts can be solved in two basic variants. The first variant is a continuous shaft - a 'chimney' (Fig. 2a) that should create a single fire compartment up the height of a building, i.e. a shaft covering (masonry, prefabricated wallboard system) with specific fire resistance, inspection doors into the shaft that are fire-rated, and fire sealing of service penetrations through fire-dividing constructions. The 
second variant is a horizontally separated shaft (Fig. 2b). The shaft space is fire sealed at the level of the floor slab and this space in-between creates a single fire compartment, or this space is a part of a fire compartment in a storey (e.g. part of an apartment). The interruption or elimination of fire and acoustic bridges through the shaft space between the storeys is the basic function of the ceiling barrier.

\section{EXPERIMENTAL SET-UP}

The experiment was carried out in the fire laboratory at the HSH University College in Haugesund. The shaft model was built under the exhaust hood of an ISO 9705 test room [3]. The interior of the fire laboratory was heated (testing in February) and the temperature level was around $20{ }^{\circ} \mathrm{C}$ during the experiment. The amount of gas used was measured with a positive displacement meter. Considering the whole set-up the amount of gas was determined with an error less than $5 \%$.

In the first variant of the shaft fire experiment, a model of a continuous empty shaft with an inert (noncombustible) covering was made. The results of this variant are discussed further.

There is also an experiment variant planned for a continuous shaft with combustible material installed which should represent a combustible shaft covering, and an experiment variant for a separated shaft with an installed ceiling partition. The former will be focused on the problems of flame spread while the latter on the behaviour of a smoke layer above and below the ceiling partition.

\section{Laboratory Shaft Model}

The cross-sectional dimensions of an inert continuous shaft come from the dimensions of commonly used apartment plumbing shafts (Fig. 1a) and its height corresponds to approximately one and a half storeys (Fig. 3). With respect to laboratory conditions, a half-scale shaft model is constructed.

The whole shaft model is constructed with light-weight concrete blocks $(600 \times 400 \times 100 \mathrm{~mm})$ laid dry (i.e. without any adhesive). The joints between the blocks were cemented from the outside. The combustion air supply is provided by an inlet tunnel in the lower part of the shaft and its function is the partial stabilization of the air flow, i.e. elimination of turbulence near the gas burner.

The propane gas burner is situated at the bottom in contact with the front shaft wall. The burner consists of a metal box (dimensions $100 \times 200 \mathrm{~mm}$, height $75 \mathrm{~mm}$ ) with gravel filling for gas dispersion. The thermal output of the burner of around $20 \mathrm{~kW}$ provides an appropriate height of flames in the lower half of the shaft.

\section{Measuring Devices}

The arrangement and labelling of the measuring devices is shown in Fig. 3. During the experiment, the following were measured:

- Temperatures at 22 points;

- Flow velocity inside the shaft at two points and inside the inlet tunnel at two points;

- Total heat flux in the vertical axis of the back shaft wall at five points.

The temperature was measured by thermocouples (2-wire Type-K devices, diameter $0.8 \mathrm{~mm}$, time constant less than $15 \mathrm{~s}$ located in two groups at a height of $0.4 \mathrm{~m}$ above the shaft bottom (height level is marked as "b") and at a height of $1 \mathrm{~m}$ (level "c") where each group has nine thermocouples. Another four thermocouples are located nearby to the flow velocity sensors.

Flow velocity was measured by two bidirectional sensors (probes) located together with another two thermocouples inside the middle part of the inlet tunnel at a height of $0.075 \mathrm{~m}$ (level "a") and a similar set $(2+2)$ is located inside the upper part of the shaft at a height of $1.4 \mathrm{~m}$ (level "d"). Each sensor is made from a hollow cylinder probe with an inner diameter of $14 \mathrm{~mm}$.

Total heat flux (convective and radiative) was measured by a water-cooled heat flux sensor (SchmidtBoelter type; SBG01-10) located in the vertical axis of the back shaft wall at five different positions. There was one sensor available and it was necessary to change the position of the sensor during the experiment. There were five holes drilled in the back shaft wall where one hole was always filled by the sensor and the others were plugged. 

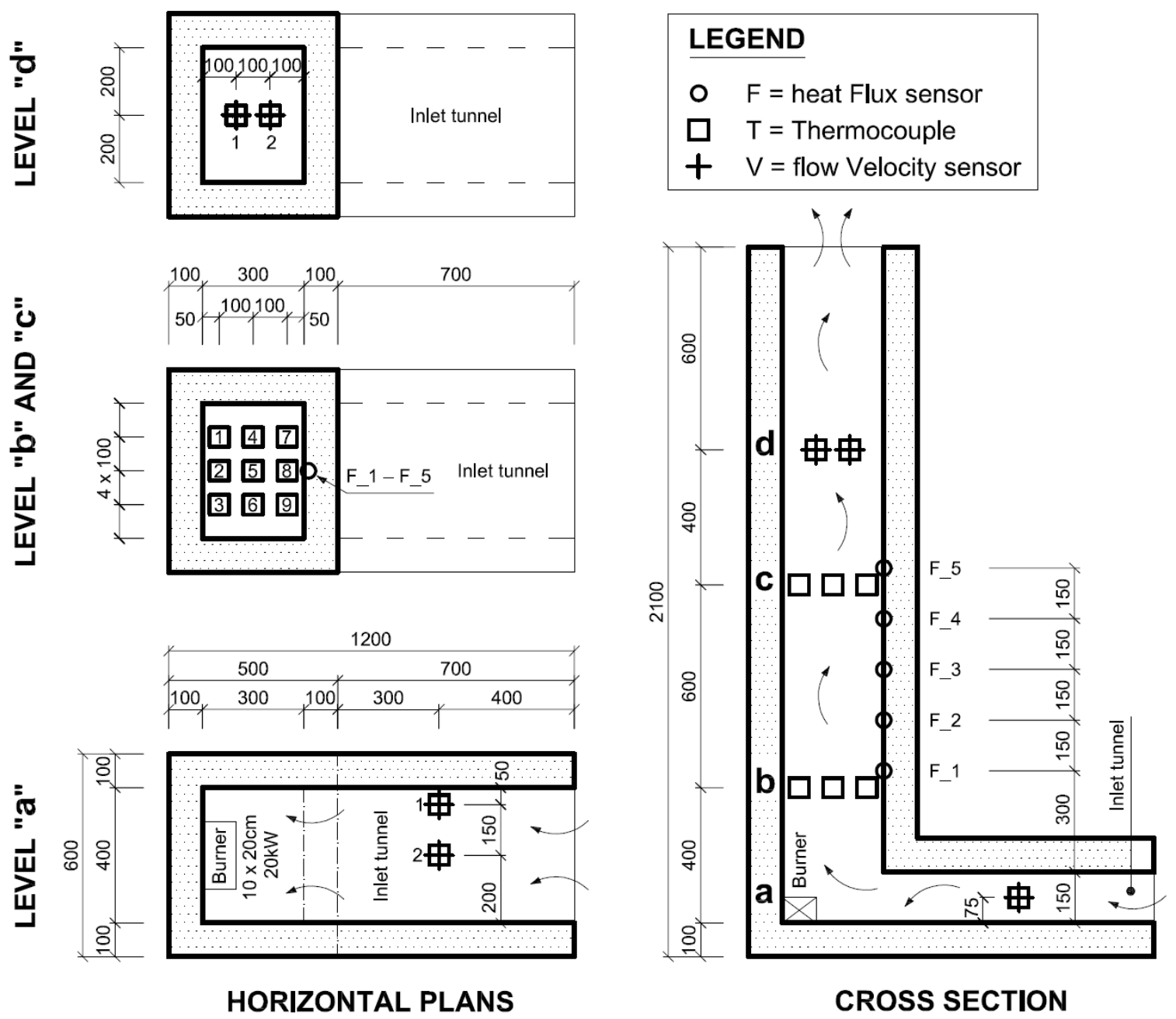

Fig. 3. Laboratory shaft model, including arrangement and labelling of measuring devices.

All measuring devices are labelled in accordance with Fig. 3. The abbreviations are used in the following graphs, where for example T_b_2 (lab) "T" is a thermocouple ("F" = heat flux sensor, "V" = flow velocity sensor) at the height level " $b$ " and in the horizontal position "2". The abbreviation "(lab)" marks a value measured in the fire laboratory, or "fds" marks results gained by computational simulation in the FDS software.

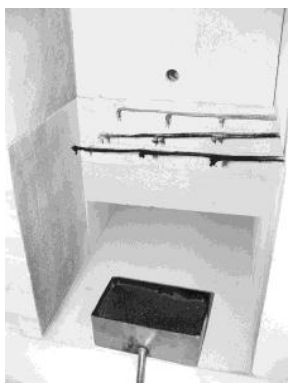

(a)

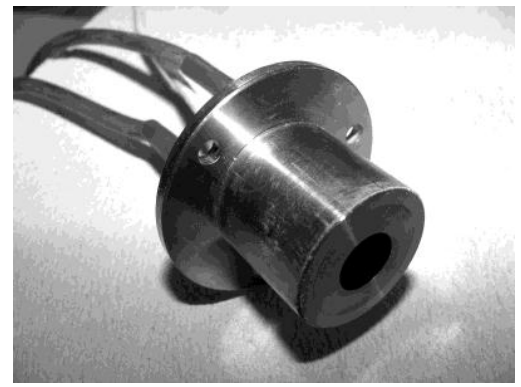

(b)

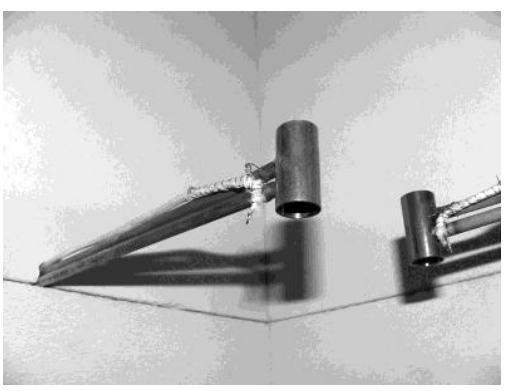

(c)

Fig. 4. Measuring devices: (a) lower group of 9 thermocouples (level "b") and the propane gas burner; (b) water-cooled heat flux sensor - Schmidt-Boelter type; (c) bidirectional flow velocity sensors including thermocouples (level "d"). 
All measuring devices were interconnected with a data logger (type Agilent 34970A) where all data are scanned at $5 \mathrm{~s}$ intervals and consequently saved in a computer. Temperature measurement was direct, i.e. in degrees Celsius and no recalculation was necessary. On the other hand, heat flux and flow velocity measurements were indirect. For heat flux, an electric potential difference measured in volts was subsequently recalculated into $\mathrm{kW} / \mathrm{m}^{2}$. In a similar way, flow velocity measured as a pressure difference in pascals was recalculated into $\mathrm{m} / \mathrm{s}$.

\section{Duration of the Experiment}

The duration of the experiment was determined by the heat flux measurement. The sensor measured for $5 \mathrm{~min}$ in five different positions and approximately $1 \mathrm{~min}$ was necessary for manual removal of the sensor and the exchange of position. The total experimental time was $30 \mathrm{~min}$. Another three tests $(15,20$ and 25 min) were done and all tests showed very similar results as the longest test that was chosen as being representative.

\section{RESULTS FROM EXPERIMENT}

\section{Temperature Measurement}

The temperatures measured in the lower group of thermocouples (level "b") are markedly higher in comparison with the upper group (level "c"), particularly for the thermocouples close to the front shaft wall above the burner (Figs. 5a, b). The highest temperature of around $600{ }^{\circ} \mathrm{C}$ measured by the middle thermocouple (T_b_2) drops to values between 400 and $500{ }^{\circ} \mathrm{C}$ at the edges of the shaft. The right thermocouple (T_b_3) shows a slightly higher temperature than the left one (T_b_1). The middle and the back row of thermocouples (T_b_4 - T_b_9) then show similar temperatures of about $200^{\circ} \mathrm{C}$.

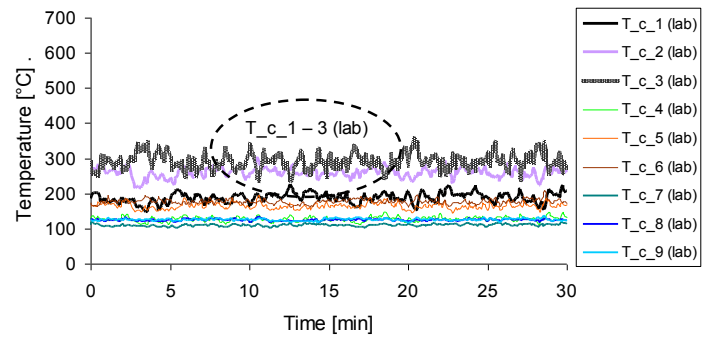

(a)

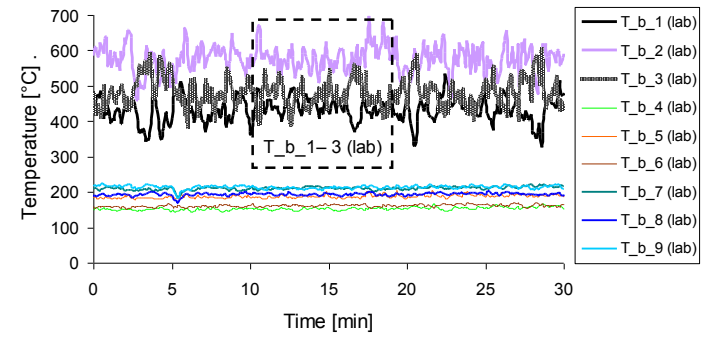

(b)

Fig. 5. Temperature measurements: (a) upper group of nine thermocouples at level "c"; (b) lower group of nine thermocouples at level "b".

In the upper group of thermocouples (level "c"), temperatures are generally lower. The inclination of the temperature field to the right hand side of the shaft during the whole test time $(30 \mathrm{~min})$ is an interesting fact but only on height level "c" (Fig. 5a). Thermocouple T_c_3 shows a higher temperature (ca. $300{ }^{\circ} \mathrm{C}$ ) than the middle one, T_c $\_2,\left(\mathrm{ca} .250^{\circ} \mathrm{C}\right.$ ). The inclination could be caused by imperfect gas dispersion inside the burner, by boundary conditions in the fire laboratory or possibly, by an imperfect measuring ability of the thermocouple.

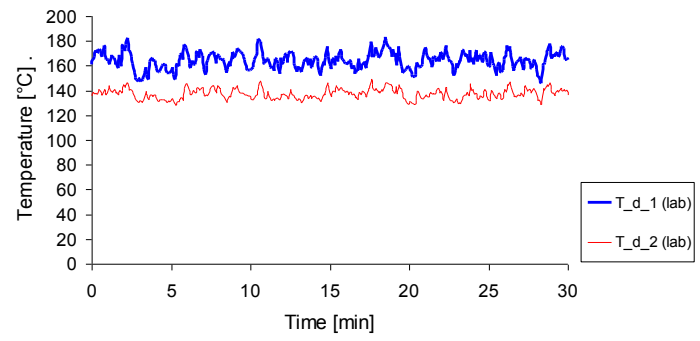

(a)

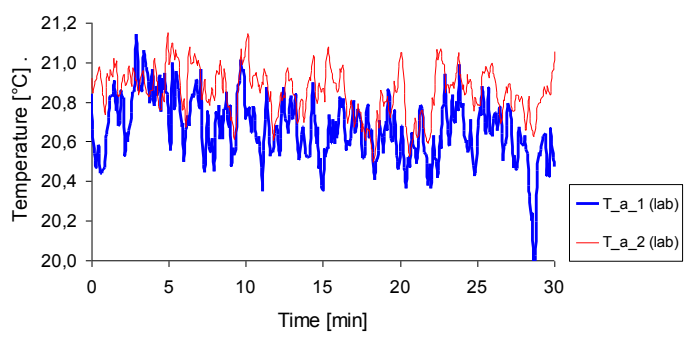

(b)

Fig. 6. Temperature measurement by thermocouples nearby flow velocity sensors: (a) level "d"; (b) level "a" (inlet tunnel). 
The temperatures measured by two thermocouples $\left(\mathrm{T} \_\mathrm{d} \_1\right.$ and $\left.\mathrm{T} \_\mathrm{d} \_2\right)$ near to the flow velocity sensors in the upper part of the shaft (level "d") similarly range between 140 and $180^{\circ} \mathrm{C}$. The temperatures measured by the two thermocouples inside the inlet tunnel follow the interior temperature of the laboratory room, i.e. around $20^{\circ} \mathrm{C}$. A slightly higher value is measured in the middle part of the inlet tunnel, a lower temperature than close to the side wall.

\section{Total Heat Flux Measurement}

The total heat flux is calculated using the measured data in volts and the sensitivity constant of the sensor:

$q=\frac{U .1000}{s}$

where: $q$-Total heat flux $\left(\mathrm{kW} / \mathrm{m}^{2}\right)$

$U$ - Measured value of the electric potential difference $(\mathrm{mV})$

$s=0.578\left(\mathrm{mV} \cdot \mathrm{m}^{2} / \mathrm{kW}\right)-$ sensitivity constant for the heat flux sensor.

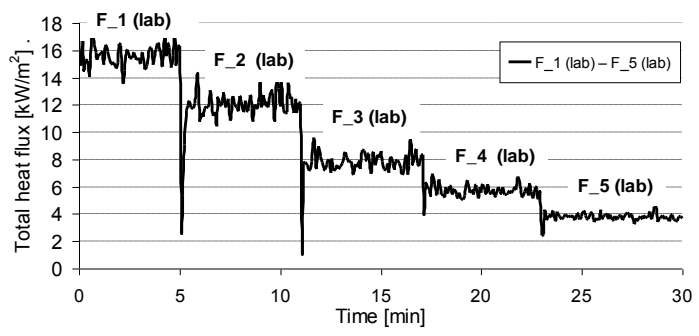

Fig. 7. Total heat flux measurement - the curve represents values measured by one heat flux sensor in five different positions in the vertical axis of the back shaft wall.

The measurement of the total heat flux in each of 5 positions shows average values of about 15.5, 12, 8, 5.5 and $4 \mathrm{~kW} / \mathrm{m}^{2}$.

\section{Flow Velocity Measurement}

The pressure difference $(\Delta p)$ measured by bidirectional flow velocity sensors was recalculated into flow velocity $(\mathrm{m} / \mathrm{s})$ as described in the Appendix.

In the upper part of the shaft, a higher value of flow velocity (ca. $2.5 \mathrm{~m} / \mathrm{s}$ ) was measured by the sensor close to the front wall (above the burner) in comparison with the sensor close to the back shaft wall (ca. $1.5 \mathrm{~m} / \mathrm{s}$ ). In the inlet tunnel, a slightly higher value was measured in the middle part of the inlet tunnel (ca. $3.0 \mathrm{~m} / \mathrm{s}$ ), a lower value than nearby to the side wall (ca. $2.5 \mathrm{~m} / \mathrm{s}$ ). This shows there is a nearly fully-developed turbulent profile in the inlet tunnel.

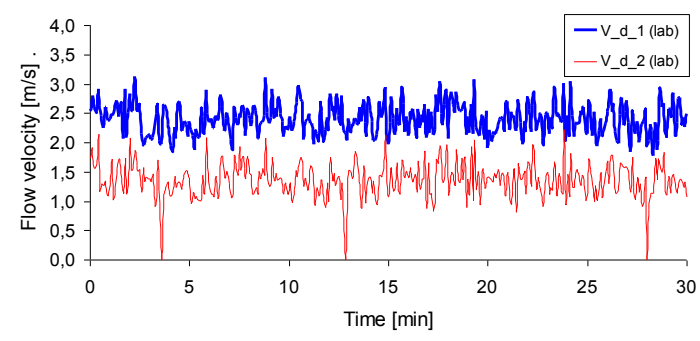

(a)

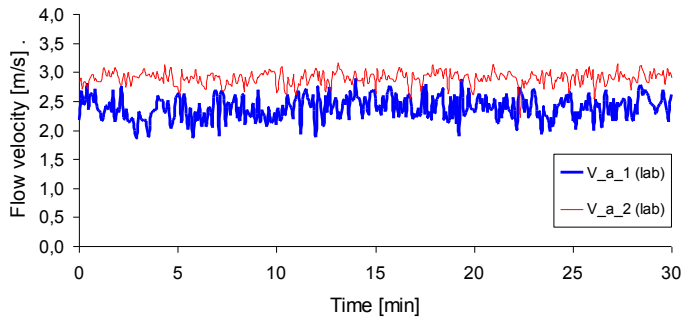

(b)

Fig. 8. Velocity flow measurement: (a) level "d"; (b) level "a" (inlet tunnel). 


\section{SIMULATION SET-UP}

Version 5.5.2 of the Fire Dynamics Simulator (FDS) software is used. The computational domain was divided into two computational meshes with the size of all cubic cells being $25 \mathrm{~mm}$. The first mesh with 15,360 cells corresponds to the shaft space and the second smaller mesh with 3,072 cells to the inlet tunnel. No shaft obstructions were modelled (walls, a bottom or a ceiling above the inlet tunnel) and they are defined by their material properties and thickness as default values on boundaries of the computational domain. The simulation time was $20 \mathrm{~min}$ and the default large eddy simulation (LES) was used.

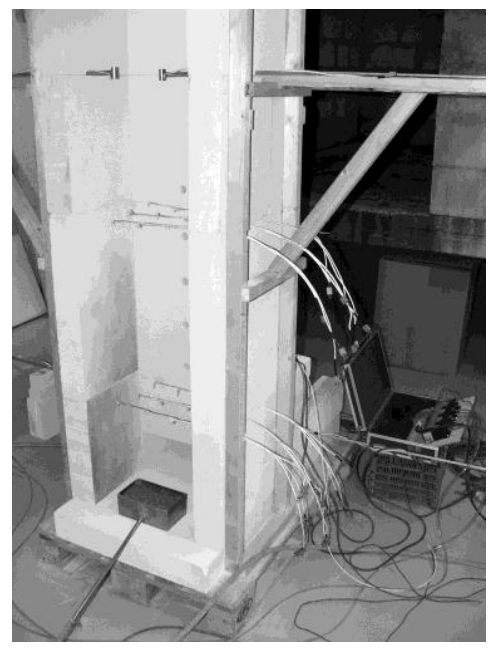

(a)

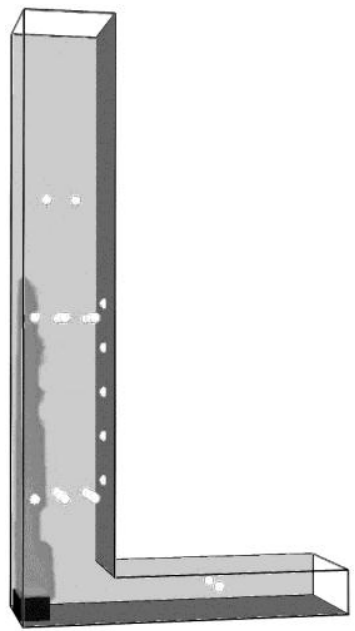

(b)

Fig. 9. (a) Laboratory shaft model (without the front shaft wall); (b) shaft model in the Smokeview software (version 5.5.8; the visualization tool of the FDS software).

The fineness of the computational mesh was chosen on the basis of the ratio of the characteristic fire diameter $D^{*}$ and the size of the cell $d x$. This ratio should oscillate in the optimal interval of 4-16 [4]. A bigger value $D * / d x$ means a finer mesh, more detailed and more accurate computation, and a longer computational time also. For the computational domain with cubic cells of $25 \mathrm{~mm}$ and for the heat output of the burner of $20 \mathrm{~kW}$, it is possible to calculate the ratio using the following formula [4]:

$\frac{D^{*}}{d x}=\frac{\left(\frac{\dot{Q}}{\rho_{\infty} \cdot c_{p} \cdot T_{\infty} \cdot \sqrt{g}}\right)^{2 / 5}}{d x}=\frac{\left(\frac{20}{1.204 \cdot 1 \cdot 005 \cdot 293 \cdot \sqrt{9.81}}\right)^{2 / 5}}{0,025}=\frac{0.201}{0.025}=8.0$

For comparison, the following table also shows different values of $D * / d x$ for finer meshes with cubic cells of 10 and $5 \mathrm{~mm}$.

Table 1. Efficiency of various computational meshes.

\begin{tabular}{|l|r|r|}
\hline Size of cell (mm) & Number of cells & \multicolumn{1}{c|}{$\boldsymbol{D} * / \boldsymbol{d} \boldsymbol{x}$} \\
\hline $25 \times 25 \times 25$ & 18,432 & 8.0 \\
\hline $10 \times 10 \times 10$ & 288,000 & 20.1 \\
\hline $5 \times 5 \times 5$ & $2,304,000$ & 40.2 \\
\hline
\end{tabular}

\section{RESULTS FROM SIMULATION}

Some of the graphs from the FDS simulation have a large fluctuation with respect to time and therefore they were replaced by a moving average function (in Microsoft Excel) for easier orientation. 


\section{Temperature Simulation}

If the results from 2 thermocouples directly above the burner (T_b_2 and T_c_2) are compared, it is possible to observe an interesting phenomenon. The higher thermocouple $(1 \mathrm{~m}$ above the burner) predicts a higher temperature, of around $350{ }^{\circ} \mathrm{C}$, than the lower thermocouple $(0.4 \mathrm{~m}$ above the burner) that predicts a temperature of only around $150{ }^{\circ} \mathrm{C}$ (Figs. $10 \mathrm{a}, \mathrm{c}$ ). This phenomenon was not observed during the whole experiment measurement. In this case, it is convenient to analyse not only the graphs but to analyse contrasting visualizations (iso-contours) generated by the Smokeview software. In Fig. 12 as well, there is an obvious inclination of a temperature field towards the front shaft wall first and above the lower group of thermocouples (level "b"), the temperature field inclination then goes back from the front shaft wall, which explains the "illogical" inverse shape of the temperature curves in the graphs.

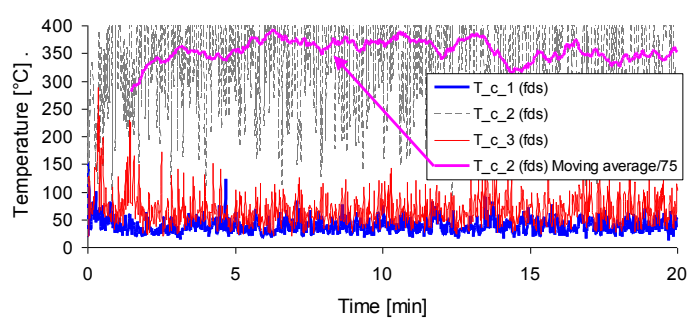

(a)

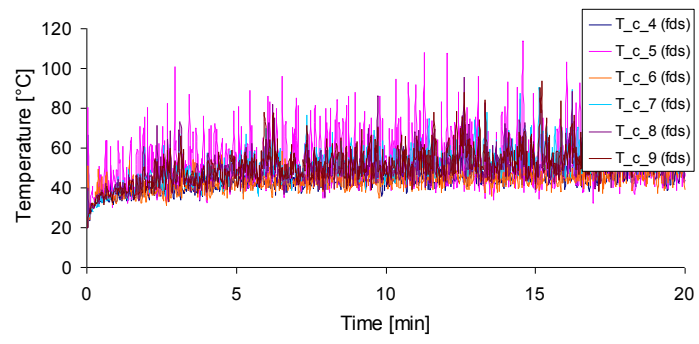

(b)

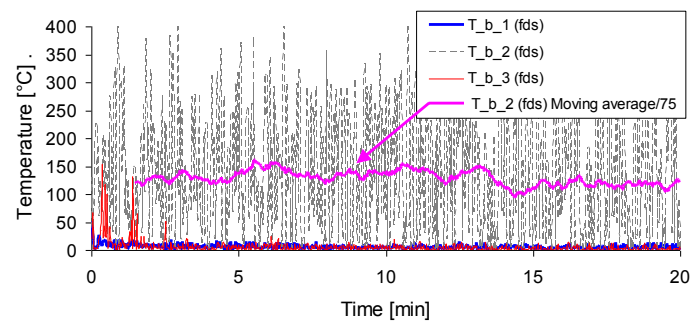

(c)

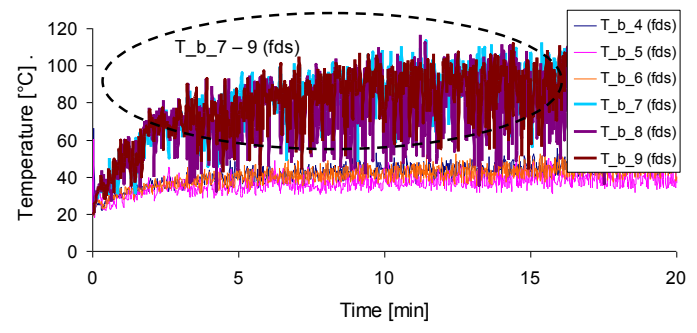

(d)

Fig. 10. Temperature simulation by thermocouples: (a) T_c_1 - T_c_3 (upper group); (b) T_c_4 - T_c_9 (upper group); (c) T_b_1 - b_3 (lower group); (d) T_b_4 - T_b_9 (lower group).

The next unusual feature in the whole simulation time can be observed in the lower group of thermocouples (level "b") in Fig. 10d. The middle row of thermocouples (T_b_4, T_b_5 and T_b_6) are closer to the gas burner but they indicate markedly lower temperatures than the thermocouples nearby to the back shaft wall. The middle thermocouples predict only around $40{ }^{\circ} \mathrm{C}$, while the back ones measure temperatures more than double. This phenomenon of a warmer air flow along the back shaft wall is obvious on the contrasting isocontour also (Fig. 12b) where lighter colour indicates a warmer area.

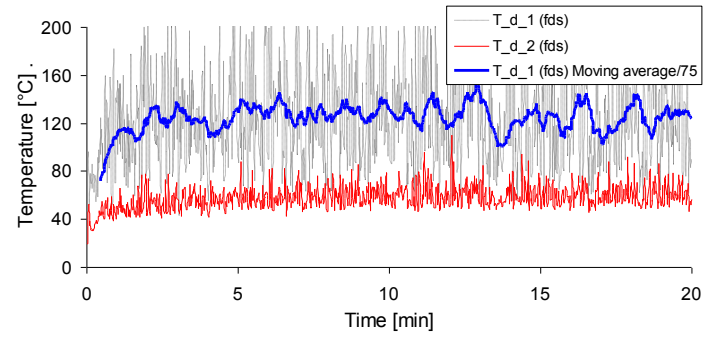

(a)

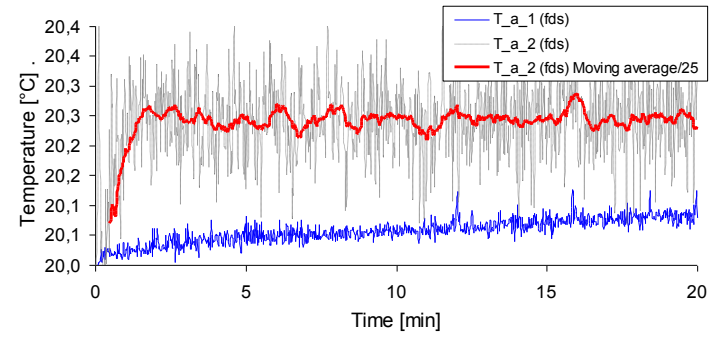

(b)

Fig. 11. Temperature simulation by thermocouples nearby to flow velocity sensors: (a) level "d"; (b) level "a" (inlet tunnel). 


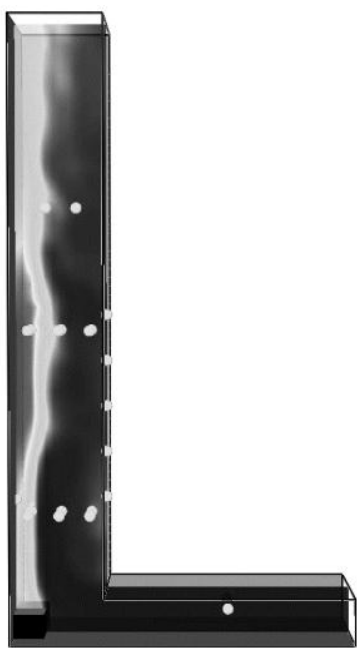

(a)

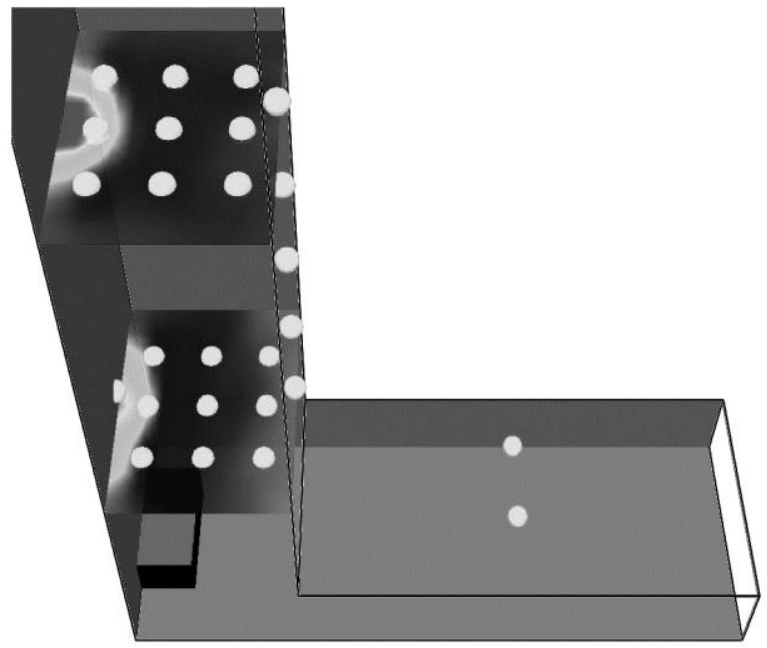

(b)

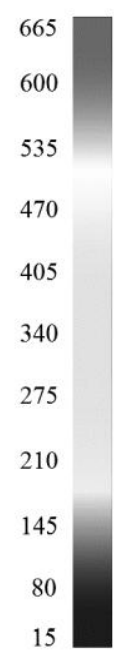

Fig. 12. Temperature simulation in colour iso-contours: (a) in the longitudinal vertical plane led in the middle of the shaft; (b) in horizontal planes led on level "b" (height $0.4 \mathrm{~m}$ ) and "c" (height $1 \mathrm{~m}$ ).

Thermocouple T_d_1 in the upper part of the shaft (level "d") close to the front shaft wall (above the burner) predicts a higher temperature (ca. $120{ }^{\circ} \mathrm{C}$ ) than thermocouple T_d_2 close to the back shaft wall (ca. $60^{\circ} \mathrm{C}$ ). The temperatures measured by 2 thermocouples inside the inlet tunnel (level "a") follow the initial temperature of around $20^{\circ} \mathrm{C}$ set as a boundary condition. A slightly higher value is measured in the middle part of the inlet tunnel (T_a_2), a lower temperature than close to the side wall (T_a_1).

\section{Total Heat Flux Simulation}

The total heat flux (convective plus radiate) was set as 'gauge heat flux' in the FDS input file because of using the water-cooled sensor in the experiment. All curves have an increasing pattern until around the $18^{\text {th }}$ minute when predicted values in each of five positions show around $16.5,15,12,8.5$ and $5.5 \mathrm{~kW} / \mathrm{m}^{2}$.

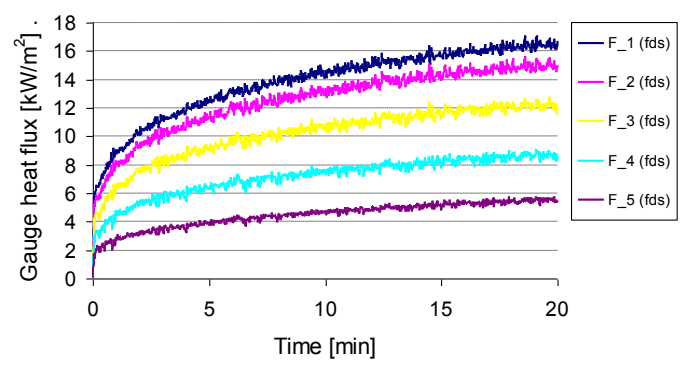

Fig. 13. Total (gauge) heat flux simulation in 5 different vertical positions in the axis of the back shaft wall.

\section{Flow Velocity Simulation}

In the upper part of the shaft, a higher value of flow velocity (ca. $2.2 \mathrm{~m} / \mathrm{s}$ ) from the sensor close to the front the wall (above the burner) is predicted in comparison with the sensor close to the back shaft wall (ca. $1 \mathrm{~m} / \mathrm{s}$ ) - Fig. 14a. On the other hand, an identical flow velocity for both sensors in the inlet tunnel is predicted (Fig. 14b). 


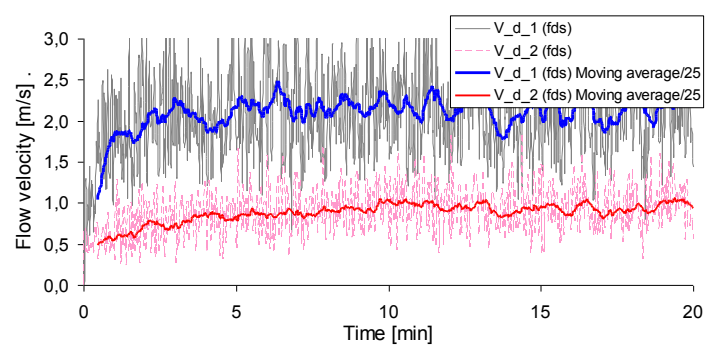

(a)

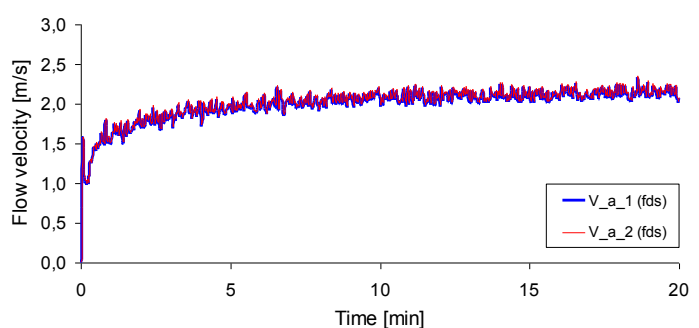

(c)

Fig. 14. Velocity flow simulation: (a) level "d"; (b) level "a" (inlet tunnel).

\section{MEASUREMENT UNCERTAINTY}

The uncertainty of the temperature measurements is less than $1 \%$ for the measurement in the inlet tunnel. For the temperature measurement in the shaft the error is larger due to the use of unshielded thermocouples, although the thermocouples are small [5]. In the measurement set-up in the shaft the thermocouples will measure temperatures that are too high and it is estimated that the error can be up to $20 \%$.

The uncertainty of the velocity measurements in the inlet tunnel is about $5 \%$ based on findings by McCaffrey and Heskestad [6]. The bidirectional probe is also sensitive to angular deviation (misalignment) and this error can be up to $4 \%$ for a misalignment of $5^{\circ}$, as pointed out in the paper by Sette [7].

The uncertainty for the heat flux measurements is due to the primary calibration set-up and is below $\pm 3 \%$ (Anderson and Wetterlund [8]). In the actual measurements, the uncertainty is estimated to be $\pm 10 \%$.

\section{COMPARISON AND DISCUSSION}

In the followings graphs, the data presented above from laboratory measurements (lab) and FDS simulation (fds) are mutually compared.

\section{Temperature Comparison}

The temperatures on all height levels ("a"-"d") simulated by the FDS software predict lower values in comparison with laboratory measurements. The only exception is thermocouple T_c 2 directly above the burner at level "c" that predicts higher values (Fig. 15a). The FDS software concentrates higher temperatures into a narrow space above the burner, and temperatures are then lower in the rest of the shaft space (Fig. 12).
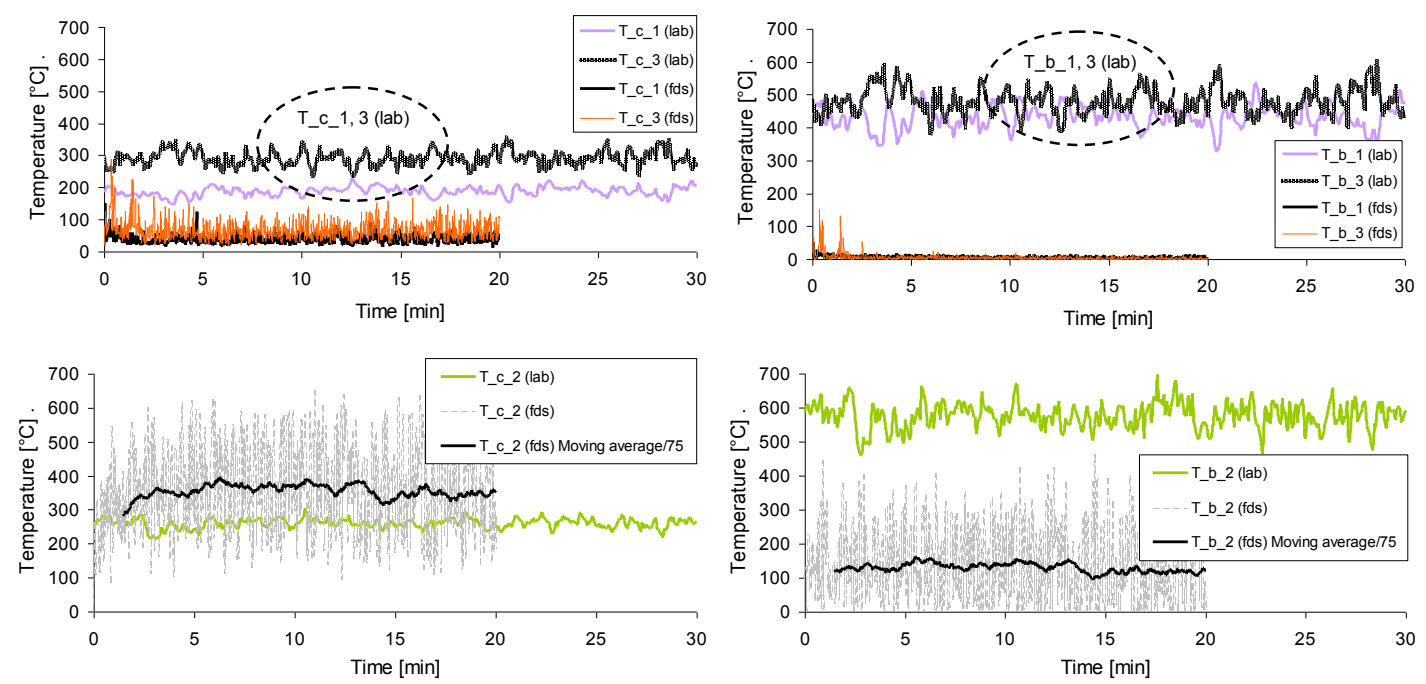

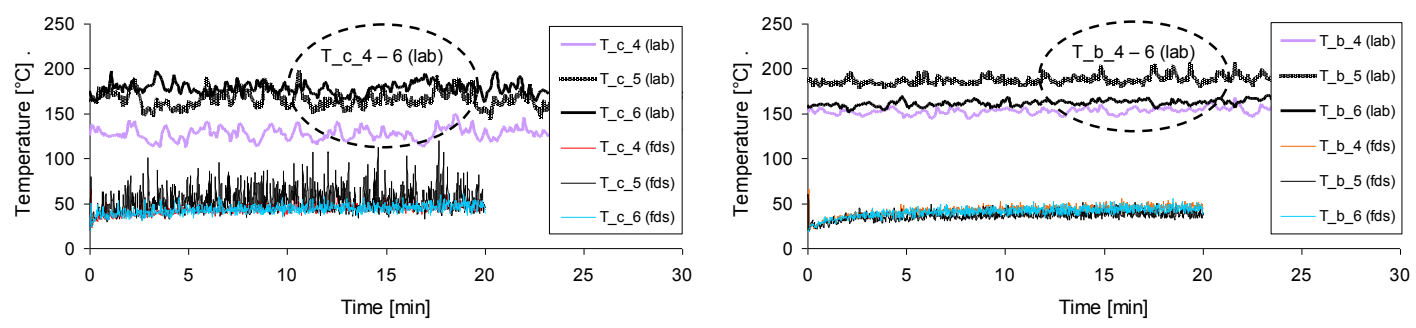

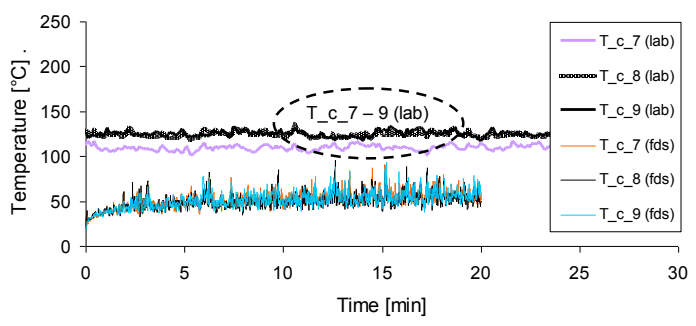

(a)

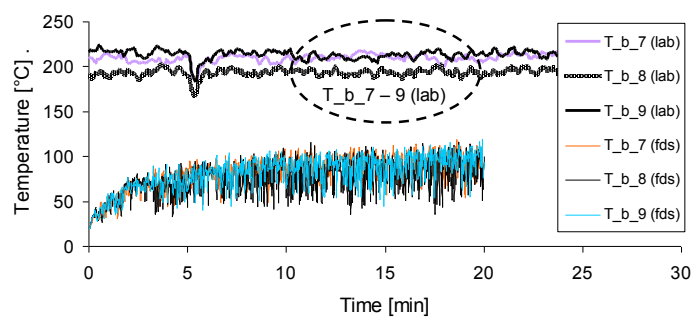

(b)

Fig. 15. Temperature comparison between laboratory measurements and FDS simulation for the group of thermocouples: (a) level "c" (T_c_1 - T_c_9); (b) level "b" (T_b_1 - T_c_9).

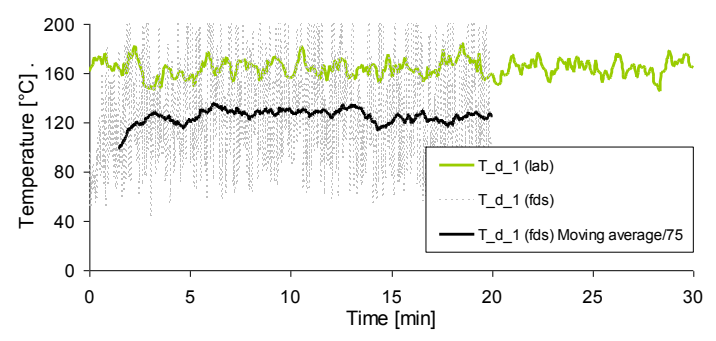

(a)

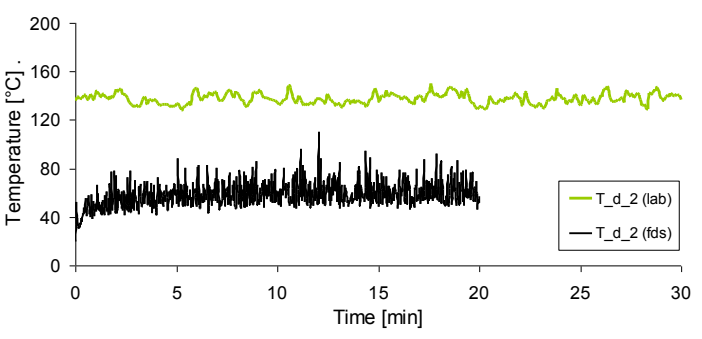

(b)

Fig. 16. Temperature comparison between laboratory measurements and FDS simulation for the highest located thermocouples in the shaft: (a) thermocouple T_d_1 close to the front wall above the burner; (b) thermocouple T_d_2 close to the back shaft wall.

\section{Total Heat Flux Comparison}

As noted above, all total (gauge) heat flux curves from the FDS simulation have an increasing pattern until around the $18^{\text {th }}$ minute (Fig. 17). The following Table 2 and the graph in Fig. 17 compare the simulated and measured data. In comparison with the temperature assessment, FDS predicts higher values of total heat flux in comparison with laboratory measurement.

Table 2. Comparison of total (gauge) heat flux between laboratory measurements and FDS simulation.

\begin{tabular}{|c|r|r|}
\hline \multicolumn{4}{|c|}{ Total (gauge) heat flux $\left(\mathbf{k W} / \mathbf{m}^{2}\right)$} \\
\hline Sensor position & Laboratory measurement & FDS simulation $\left(\mathbf{1 8}^{\text {th }}\right.$ minute) \\
\hline F_1 & 15.5 & 16.5 \\
\hline F_2 & 12.0 & 15.0 \\
\hline F_3 & 8.0 & 12.0 \\
\hline F_4 & 5.5 & 8.5 \\
\hline F_5 & 4 & 5.5 \\
\hline
\end{tabular}




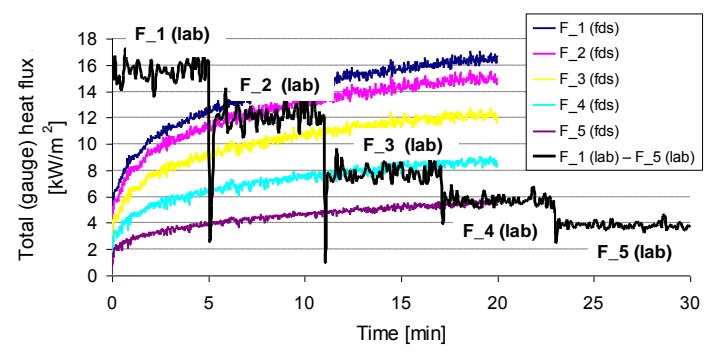

Fig. 17. Total (gauge) heat flux comparison between laboratory measurements and FDS simulation.

\section{Flow Velocity Comparison}

In Figs. 18c and d, it is possible to compare the results from the inlet tunnel that are not affected by radiation or convection from the fire (burner). For the flow velocity sensors inside the inlet tunnel in particular, additional FDS simulation for the computational mesh with $10 \mathrm{~mm}$ cubic cells was carried out. The meshes with 10 and $25 \mathrm{~mm}$ cells have almost identical values and curve patterns, only the $10 \mathrm{~mm}$ curve has a more variable shape (Figs. 18c, d). The fineness of the computational mesh has no effect in this case.

The flow velocity measurements correspond quite well with the FDS simulation, both for the sensors inside the shaft and the sensor close to the side wall of the inlet tunnel. Only the central sensor inside the inlet tunnel (V_a_2) measured a markedly higher flow velocity (ca. $3 \mathrm{~m} / \mathrm{s}$ ) in comparison with the FDS simulation (ca. $2 \mathrm{~m} / \mathrm{s}$ ) - Fig. 18d. The reason for this could be that the exhaust ventilation in the hood increases the air flow in the tunnel, although it was set at minimum level.

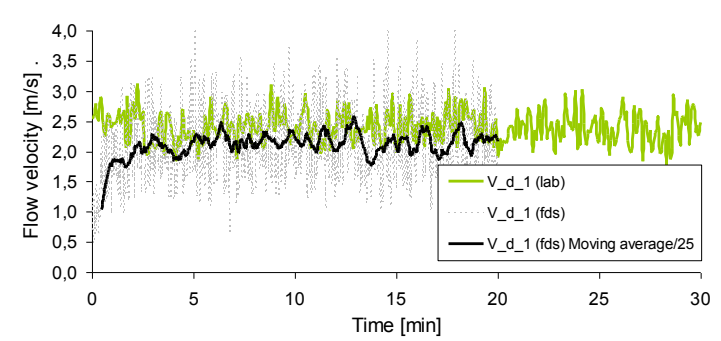

(a)

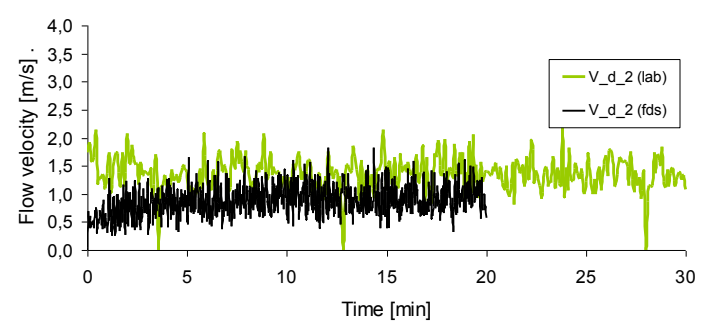

(b)

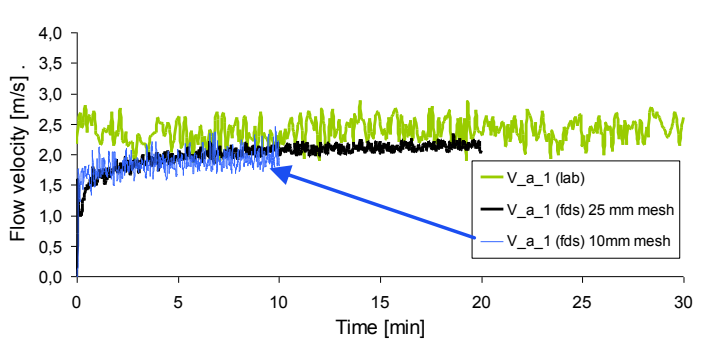

(c)

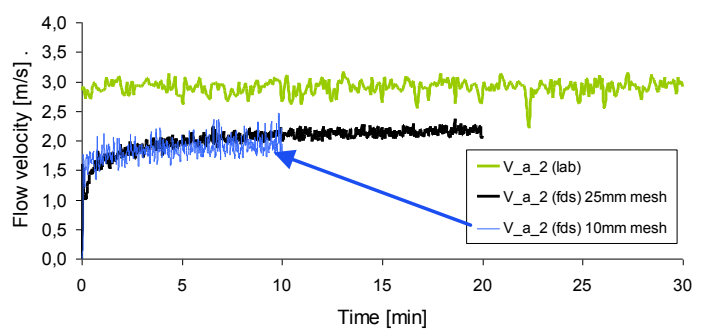

(d)

Fig. 18. Flow velocity comparison between laboratory measurement and FDS simulation for: (a) sensor V_d_1 close to the front shaft wall above the burner; (b) sensor V_d_2 close to the back shaft wall; (c) sensor $\mathrm{V} \_\mathrm{a} \_$1 close to the side wall of the inlet tunnel; (d) sensor $\mathrm{V} \_\mathrm{a} \_2$ in the centre of the inlet tunnel.

\section{CONCLUSION}

The temperature, flow velocity and heat flux distribution from the burner inside the non-combustible shaft model were measured in a laboratory set-up. The shaft set-up was also simulated in Fire Dynamics Simulator (version 5.5.2) with two different grid sizes using the LES turbulence model. The experimental data and simulated data were compared. 
As expected, the difference between the measured and calculated temperature in the inlet tunnel is small. The FDS software predicts lower values of temperatures at 19 of 20 measuring points inside the shaft model in comparison with the laboratory measurements.

In terms of temperature distribution, the FDS software concentrates higher temperatures into a narrow space directly above the gas burner, and temperatures are then lower in the rest of the shaft space (Fig. 12). The laboratory experiment showed a more even spread over the shaft space, i.e. at longer distances from the burner. One reason for the higher temperatures measured can be the fact that the thermocouple material is heated by radiation from the fire and therefore the thermocouples will show higher temperatures than the actual real temperature, but this cannot entirely explain the difference, even when the measurement uncertainty is taken into account. Another reason for these discrepancies is how the combustion and radiation are modelled in FDS, and a way to overcome this would be to implement a model for soot formation and soot tracking in FDS.

The flow velocity measurements correspond relatively well to the FDS simulation, both for the sensors inside the shaft and the sensor close to the side wall of the inlet tunnel. Higher differences are observed for the central sensor inside the inlet tunnel. Generally, at all measuring points, slightly lower values of the flow velocity distribution are simulated in comparison with laboratory measurement.

On the other hand, higher values of the heat flux distribution are simulated at all measuring points in comparison with the laboratory measurements. The difference is up to about $50 \%$ and increases with the height above the fire and this supports the theory that the shape of the flame and flame temperature are different in the simulation compared to the experimental results. This would have implications for the simulation of flame spread, as higher radiation levels in the simulation will increase the pre-heating of combustible material and the rate of spread. According to the paper by Orloff et al. [9] radiation can account for $75 \%$ to $85 \%$ of the total heat transfer on thick PMMA slabs (PMMA has been used in subsequent experiments by the authors).

The results and experience obtained will be used for the authors' continuing research of shaft fire and flame spread problems. The same shaft model with the combustible material (PMMA slabs) installed as shaft covering was already tested in two different variants and it should represent the issues mentioned of combustible covering of plumbing shafts or combustible inner content (plumbing). These new results will be presented in a following paper and in the primary author's $\mathrm{PhD}$ thesis.

\section{ACKNOWLEDGMENT}

This experimental project is part of the $\mathrm{PhD}$ thesis of the primary author and it has received support from the Research Council of Norway, and scientific, technical and material support from the Department of Engineering at Stord Haugesund University College in Norway.

\section{REFERENCES}

[1] Kupilik, V., Fire Protection of Constructions, Hungary, Dunamenti Tüzvédelem Zrt, 2009, p. 182.

[2] Vonásek, V., Lukeš P. et al., "Statistická ročenka 2009, Česká republika (Statistical Yearbook 2009, Czech Republic)," př́loha časopisu 112 No. 3, MV - generální ředitelství HZS ČR, Prague, 2010, p. 40, [in Czech].

[3] ISO 9705, Fire tests -- Full-scale room test for surface products, International Organization for Standardization, Geneva, Switzerland, 1993.

[4] McGrattan, K., Hostikka, S. and Floyd, J., Fire Dynamics Simulator (Version 5), User's Guide, National Institute for Standards and Technology Special Publication 1019-5, Gaithersburg, MD, 2007, p. 192.

[5] Shannon, K.S., Butler, B.W., "A Review of Error Associated with Thermocouple Temperature Measurement in Fire Environments," Second International Wildland Fire Ecology and Fire Management Congress and Fifth Symposium on Fire and Forest Meteorology, American Meteorological Society, Orlando, FL, 2003, p. 7B.4. 
[6] McCaffrey, B. J. and Heskestad, G., (1976) A Robust Bidirectional Low-Velocity Probe for Flame and Fire Application, Combustion and Flame 26: 125-127, http://dx.doi.org/10.1016/0010$\underline{2180(76) 90062-6}$

[7] Sette, B.J.G., (2005) Critical Considerations on the Use of a Bi-directional Probe in Heat Release Measurements, Fire and Materials 29: 335-349, http://dx.doi.org/10.1002/fam.886

[8] Andersson, P. and Wetterlund, I., "Uncertainty in Heat Flux Calibrations Performed According to NT FIRE 050 - Nordtest project No. 1525-01," SP Report 34, Borås, Sweden, 2001, 36 p.

[9] Orloff, L., De Ris, J., and Markstein, G.H., "Upward turbulent fire spread and burning of fuel surface," Symposium (International) on Combustion, Combustion Institute, 1975, 15(1), pp. 183192, http://dx.doi.org/10.1016/S0082-0784(75)80296-7

\section{APPENDIX - FLOW VELOCITY - RECALCULATION OF MEASURED DATA}

The pressure difference $(\Delta p)$ measured by bidirectional flow velocity sensors was recalculated into flow velocity $(\mathrm{m} / \mathrm{s})$ in the following way [3], [6]:

$u=\frac{1}{K_{p}} \cdot \sqrt{\frac{2 \cdot \Delta p \cdot T}{353}}$

where: $\mathrm{u}$ - flow velocity $(\mathrm{m} / \mathrm{s}) ; K_{p}$ - correction factor depending on Reynolds number $(\mathrm{Re})$

$K_{p}=0$ for $\mathrm{Re} \leq 40 ; K_{p}=1.08$ for $\mathrm{Re} \geq 3800$

$K_{p}=-2.484^{-17} \cdot \operatorname{Re}^{5}+2.555^{-13} \cdot \operatorname{Re}^{4}-9.706^{-10} \cdot \operatorname{Re}^{3}+1.688^{-6} \cdot \mathrm{Re}^{2}-1.366^{-3} \cdot \operatorname{Re}+1.533$

(Calculation of $\mathrm{Re}$ in an iterative way for values $40<\operatorname{Re}<3800$; i.e. the unknown value of flow velocity " $u$ " is guessed in the following formula for Re)

$\Delta p$ - Pressure difference $(\mathrm{Pa}) ; T$ - measured temperature nearby the flow velocity sensor $(\mathrm{K})$

$\Delta p=\frac{U-5.5}{4.5} \cdot 12.5$

where: $\quad U$ - measured value of the electric potential difference $(\mathrm{V})$

$\operatorname{Re}=\frac{353 \cdot u \cdot D}{T \cdot \mu}$

where: $\operatorname{Re}$ - Reynolds number; $u$ - flow velocity (guessed value) $(\mathrm{m} / \mathrm{s}) ; D$ - diameter of the flow velocity sensor $(\mathrm{m}) ; T-$ measured temperature nearby the flow velocity sensor $(\mathrm{K}) ; \mu-$ dynamic viscosity $(\mathrm{kg} / \mathrm{m} \cdot \mathrm{s})$ - function of temperature

$\mu=\mu_{o} \cdot \frac{0.555 . T_{o}+C}{0.555 . T+C} \cdot\left(\frac{T}{T_{o}}\right)^{3 / 2}$

where: $\mu$-dynamic viscosity (centipoise) at input temperature $(1 \mathrm{~kg} / \mathrm{m} \cdot \mathrm{s}=1000$ centipoise)

$\mu_{o}=0.01827$ centipoise - reference viscosity at the reference input temperature $T_{O}$ (constant for standard air)

$T$ - input temperature $\left[{ }^{\circ} \mathrm{R}\right] ;$ to $=524.07{ }^{\circ} \mathrm{R}$ - reference temperature (constant for standard air)

$C=120-$ Sutherland's constant (constant for standard air) 